\title{
Heat development at the knife roller during leather shaving
}

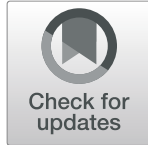

Tilman Witt $^{1 *}$ D, Anke Mondschein ${ }^{2}$, Jens-Peter Majschak ${ }^{1}$ and Michael Meyer ${ }^{2}$

\begin{abstract}
Leather, which is regularly tanned from whole hides of up to $5 \mathrm{~m}^{2}$, needs a constant thickness over the entire surface in order to be processed into high-quality consumer goods such as shoes, furniture and car interiors. Precise adjustment of the thickness is achieved by shaving. On an industrial scale, rotating knife rollers are used to remove chips from the flesh side of semi-finished leathers whereby adjusting the specified thickness and generating a smooth surface. Care must be taken to prevent the temperature from rising above the denaturation temperature of the leather during shaving in order to avoid any loss of quality. Beside this, temperature rise is always a sign of friction showing avoidable energy expenditure. In order to localize the source of friction during shaving, actual temperature development at the roller knife is studied. Different measuring methods are used to evaluate the temperature increase at the blade roll of the shaving machine. The finite element method is used to thermally simulate the process. Measured temperatures, the geometry of the blade roll and process data are taken into account for modelling the temperature development close to the blade edge. The obtained results enhance the understanding of temperature generating processes during machine operation and allow conclusions about potential improvements in the design of the machine and blades.
\end{abstract}

Keywords: Leather, Shaving, Knife roller, Transient thermal simulation

\section{Introduction}

In leather manufacturing, shaving is one of the most important mechanical processing steps to adjust a hide to a required thickness. Collagen fibers and fiber bundles are removed from the flesh side of a hide until the thickness of the entire hide is precisely adjusted. While thickness adjustment in an artisan tannery has been performed for hundreds of years manually by the use of fleshing knifes, electric shaving machines are existing since the 1920s [1] and are widely used today. The increase in processing speed leads to a considerable temperature load of the hides. However, elevated temperatures can damage the leather. Leather consists of collagen fibers. The collagen fibers lose their highly ordered structure and mechanical strength when heated above a certain temperature, which is defined as "temperature of denaturation" $T_{\mathrm{D}}$.

\footnotetext{
* Correspondence: tilman.witt@tu-dresden.de

${ }^{1}$ Chair of Processing Machines and Processing Technology, Technische

Universität Dresden, 01062 Dresden, Germany

Full list of author information is available at the end of the article
}

Hence, temperature of denaturation describes the resistance of leather against thermal stress. The temperature rise at the interface between knife and hide must therefore not exceed $T_{\mathrm{D}}$. Beside the triple helical structure of collagen molecules, $T_{\mathrm{D}}$ depends strongly on crosslinking of collagen, i.e. tanning. Whereas an untanned hide shows a $T_{\mathrm{D}}$ of $60^{\circ} \mathrm{C}$, tanning may rise it to up to over $100^{\circ} \mathrm{C}$. Therefore, pre-tanning is necessary in advance of the mechanical shaving step to achieve an improved resistance of the hides. Typically, leathers are pre-tanned either with chromium salts or synthetically, which rises $T_{\mathrm{D}}$ to about $100^{\circ} \mathrm{C}$ and $75^{\circ} \mathrm{C}$ to $85^{\circ} \mathrm{C}$. Vegetable tanned hides show an even lower $T_{\mathrm{D}}$ of $60^{\circ} \mathrm{C}$ to $80^{\circ} \mathrm{C}$ depending on the kind of tannin used [2]. Chromium-free tanning regains more and more interest because of concerns about sustainability and the goal of zero discharge of hazardous chemicals. However, in particular chrome-free pretanned hides could suffer damage during shaving, as their $T_{\mathrm{D}}$ is $85^{\circ} \mathrm{C}$ or below. Therefore, it is important to understand the temperature development during industrial shaving in order to derive measures that enable efficient damage free 
shaving of vegetable pre-tanned hides as well as energy savings through optimized machine parameters and knife geometry.

This paper reports for the first time on temperature measurements on the knife roller of a shaving machine in process recorded in an industrial environment. The results enable the description of the thermal behavior during the entire leather shaving process.

Process data are taken from the roller body and blades using thermistors, which are characterized by robustness, sensitivity and stability [3]. Since the maximum temperature at the contact zone between blade and leather is not measurable experimentally, it was calculated by using a finite element computer simulation model over the complete shaving process. Similar investigations have been conducted in the field of metal cutting $[4,5]$, where the occurring temperatures and a model derivation were already successfully carried out [6]. In this simulation, the geometry of the blades and roller body, machine load and a calculated heat transfer coefficient are taken into account. Results are gained by fitting the thermal energy input with regard of the measured process data. The predicted maximum temperature values help to correlate the machine parameters of the shaving process to the denaturation temperature of the hides achieved in the upstream pretanning process.

\subsection{Leather reactions to thermal stress}

Leather is made from hides and skins, which are composed of the fibril-forming collagen. The collagen molecule consists of protein-chains, which form a triple helical structure and are further arranged into a fibrillary superstructure. Heating causes hides and leathers to shrink due to collagen denaturation. The triple helices of the collagen molecule disintegrate into single strands resulting in the loss of the rod-like structure of the collagen molecule [7]. This shrinkage temperature, or more precisely, this temperature of denaturation depends on natural and, in case of (pre)-tanned hides, additional artificial crosslinks between the protein chains as well as the water content $[2,8]$.

Temperature of denaturation of fully hydrated hides (tissue) without additional crosslinking is approximately $60^{\circ} \mathrm{C}$. Crosslinking with glutaraldehyde (synthetic tannage) increases the temperature of denaturation up to $85^{\circ} \mathrm{C}$. Stabilization by chromium (III) ions increases the temperature of denaturation up to $105^{\circ} \mathrm{C}$ and more [9]. Denaturation is an irreversible and highly damaging process that must be avoided during leather manufacturing.

\subsection{The shaving machine}

Shaving machines typically consist of a knife roller (a), a grinding wheel (b) and a support roller (chromium roller) (c) as shown in Fig. 1. A shaving machine of Rizzi (type LW, built in 1987) with a working width of 3200 $\mathrm{mm}$ has been used throughout our experiments. The dimensions of the machine are typical for currently available machines, so that it is comparable to the current reference design. The main motor driving the roller is a $75 \mathrm{~kW}$ asynchronous machine, which rotates at $1000 \mathrm{~min}^{-1}$ in idle speed $n_{\text {cylinder. The torque is trans- }}$ mitted directly to the blade cylinder with a basic diameter of $315 \mathrm{~mm}$. On the blade cylinder, there are 20 leftrising and 20 right-rising helical blades. The blades show a height of $35 \mathrm{~mm}$ and are force-fitted into a $7.5 \mathrm{~mm}$ deep groove on the cylinder.

The grinding wheel spins around its axis of rotation and moves translationally along the axis of rotation. As a result, the knife cylinder is ground continuously and the sharpness of the knives remains almost constant. Relevant machine data are listed in Table 1.

The half-finished hides are handled manually by the staff. The process requires four repetitive steps. In step I the hide is inserted with the tail first, the machine is closed and two thirds of the skin is shaved. In step II the machine is opened and the hide is turned by $180^{\circ}$. In step III, the hide is inserted with the neck first and the remaining third is shaved with the machine closed taking. Finally, the hide is stacked next to the machine in step IV. During handling of the hides, all rollers of the machine move at constant speed with no contact to hide or other machine parts which allows a partial cooling of the roller and knife.

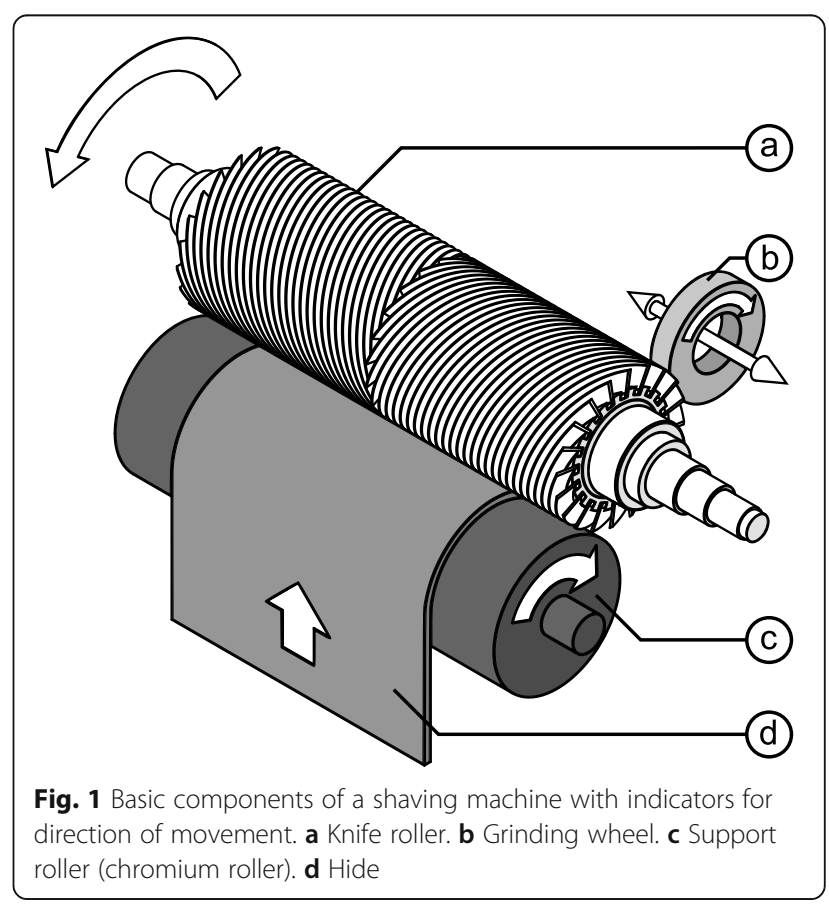


Table 1 Rizzi LW 3200 Shaving Machine Characteristics

\begin{tabular}{lll}
\hline Variable & Value & Description \\
\hline$d_{\text {cylinder }}$ & $315 \mathrm{~mm}$ & Diameter of the cylinder without blades \\
Icylinder & $3200 \mathrm{~mm}$ & Length of the cylinder \\
$h_{\text {blade }}$ & $27 \mathrm{~mm}$ & Actual height of the blades form cylinder surface \\
$s_{\text {blade }}$ & $2.5 \mathrm{~mm}$ & Thickness of the blades \\
$n_{\text {blade }}$ & 20 & Number of blades around the cylinder \\
$p_{\text {blade }}$ & $528 \mathrm{~mm}$ & Pitch of the blades \\
$n_{\text {cylinder }}$ & $1000 \mathrm{~min}^{-1}$ & Revolutions per minute of the cylinder \\
\hline
\end{tabular}

\subsection{Cutting principle and energy consumption}

The design of the machine leads to a special form of cutting. In order to produce an inclined cut with a very high gradient, a very long knife is required. A reduction in the overall dimensions of the cutting tool is achieved by shaping the blade into a rotationally symmetrical helix. The material is held outside by another roller which presses the leather onto the chrome roller and conveys it in a controlled manner [10]. By moving the blades on a circular path during sharpening, a clearance angle of zero degrees is achieved. In analogy to conventional turning and milling, high friction is expected on the blade flank [11]. Investigations have shown that motor torques $M_{\text {Motor }}$ of $100 \mathrm{~N} \cdot \mathrm{m}$ can be necessary for half cow hides even at small thickness removal. Using formula (1), a power output $P_{\text {Motor }}$ of approximately 16 $\mathrm{kW}$ can be calculated at a rotational speed $n_{\text {Motor }}$ of $1500 \mathrm{rpm}[12]$.

$$
P_{\text {Motor }}=2 \cdot \pi \cdot n_{\text {Motor }} \cdot M_{\text {Motor }}
$$

It is unknown how the mechanical energy emitted by the engine is converted or stored. The variation of the machine settings has a large effect on the thickness of the shavings chips and a small influence on the cut surface [12].

\section{Materials and methods}

\subsection{Pre tanned leathers and shaving}

Industrially pre-tanned semi-finished bovine hides were used for the trials. The hides had a width of about 2000 $\mathrm{mm}$. The hides had been soaked, limed and pre-tanned with either chromium (III) salts (Wet Blue) or glutaraldehyde (Wet White). The wet hides were sammied and stacked up. The Wet Blue hides used for the tests had an initial thickness of $2.4 \mathrm{~mm}$ to $2.5 \mathrm{~mm}$, the Wet White hides an initial thickness of $1.8 \mathrm{~mm}$ to $1.9 \mathrm{~mm}$. Water content of the hides is between $58.5 \pm 1.5 \%$. Temperature of denaturation $T_{\mathrm{D}}{ }^{\text {onset }}$ for Wet Blue was $103^{\circ} \mathrm{C}$ and for Wet White $81{ }^{\circ} \mathrm{C}$. Both, Wet Blue and Wet White were processed industrially at different feed rates. While Wet Blue has been fed with a rate of 13 $\mathrm{m} \cdot \mathrm{min}^{-1}$, Wet White was shaved at $10 \mathrm{~m} \cdot \mathrm{min}^{-1}$.

\subsection{Analysis of shaved hides}

The denaturation temperature of the pre-tanned hides was determined by calorimetric measurements using a DSC 1 (Mettler-Toledo). The samples were equilibrated in deionized water and placed in DSC pans (Al-pan; medium pressure). The pans were tightly sealed and DSC scans were performed at a scanning rate of $5^{\circ} \mathrm{C} \cdot \mathrm{min}^{-1}$ between $1{ }^{\circ} \mathrm{C}$ and $130^{\circ} \mathrm{C}$. The temperature at the beginning of the denaturation $\left(T_{\mathrm{D}}{ }^{\text {onset }}\right)$ and the maximum temperature of a DSC scan, which is $T_{\mathrm{D}}{ }^{\max }$, were determined.

The water content of pre-tanned hides and shavings was determined by drying the cut material at $102 \pm 2{ }^{\circ} \mathrm{C}$ to constant weight. The water content of the sample is calculated as the ratio of the change in mass of the sample to the initial mass before drying.

\subsection{High speed infrared imaging}

The thermal behavior of the rollerblades was recorded with a high-speed infrared camera of the type ImageIR 8300. For details of the measurement see supplemental information. For this purpose, similar to the test arrangement shown in Fig. 2, the infrared camera (a) was used to measure in the viewing direction (b) over a reflective, polished aluminum plate (c), which allowed a view of the region of interest.

The radiation of oxidized metal surfaces shows an emissivity $\varepsilon$ of 0.69 to 0.81 [13]. For the skin of pigs an emissivity of 0.96 to 0.98 could be determined [14]. Due to the movement of the blades out of the rotating roller, scanning at a constant angle is not possible. Therefore often changing alignment of the surface of interest to the measuring instrument is a challenge. Angular deviations of more than $20^{\circ}$ from the surface normal lead to distortions of the measurement $[13,15]$. Reflections can also have an influence on curved surfaces of adjacent radiating objects [15]. The use of the polished aluminium

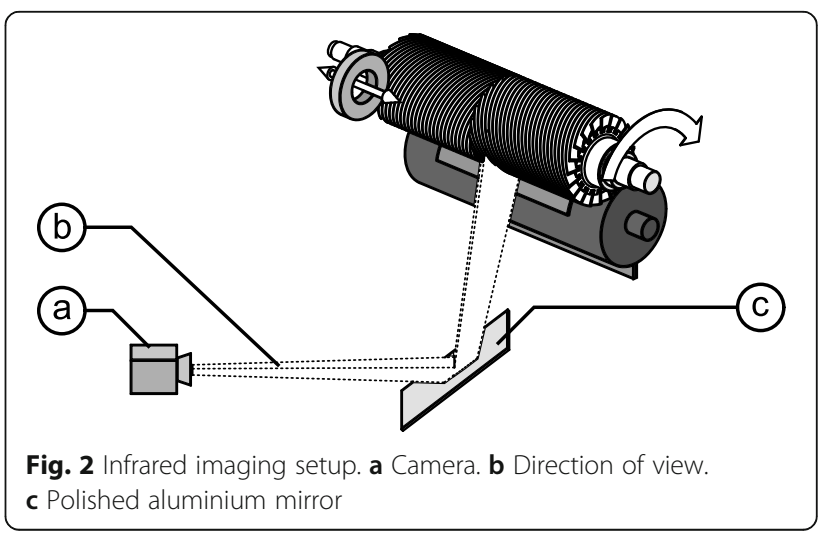


mirror results in a reduction of the emission depending on the radiation frequency [13]. The determination of the influenced emission coefficient was performed by a surface contact measurement with a thermocouple type K (National Instruments Type 745, 690-K002) at one of the blades during machine standstill. An image was generated synchronously with the thermographic camera and the radiation parameters were adjusted to the measured temperature value. Referencing was performed before and after the examination. Due to the arrangement of the measuring technique, the referencing is exclusively valid for the selected measuring setup. The individual videos had to be exported between each experiment, so a skin was shaved every $3 \mathrm{~min}$.

\subsection{Temperature measurement of the cutting tool}

A continuous measurement of the temperature of the roller blade during industrial shaving cycles was not possible by thermographic measurements due to the experimental set up with breaks between the single shaved hides. A continuous measurement of the temperature over several shaving cycles has been performed with thermistors attached to the back of the cutting tool. Thermistors of the type Negative Temperature Coefficient with the manufacturer's designation AYN-MF5B103F-3435FA-25 have been used. The thermistors have a nominal resistance $R_{\mathrm{N}}$ of $100 \mathrm{k} \Omega$ at a normal temperature $T_{\mathrm{N}}$ of $25^{\circ} \mathrm{C}$, a beta value $B$ of $3950 \mathrm{~K}$ and a tolerance of $1 \%$ for $R_{\mathrm{N}}$ and $B$. The sensors are suitable for an application range from $-30{ }^{\circ} \mathrm{C}$ to $90^{\circ} \mathrm{C}$ and have a tolerance of $\pm 2 \mathrm{~K}$. The conversion of the resistance value $R_{\mathrm{T}}$ to a corresponding temperature $T_{\text {Therm }}$ within the microcontroller is determined according to the reduced formula (2) of Steinhart and Hart [16].

$$
\frac{1}{T_{\text {Therm }}}=\frac{1}{T_{\mathrm{N}}}+\frac{1}{B} \cdot \ln \frac{R_{\mathrm{T}}}{R_{\mathrm{N}}}
$$

The thermistors were connected in series with reference resistors $R_{0}$ of $100 \pm 1 \mathrm{k} \Omega$ and the voltage was measured with an ESP32 microcontroller (Espressif Systems (Shanghai) Co., Ltd.). The microcontroller allows a theoretical resolution of 14 bit at the analog inputs and data communication via Wifi. The circuit is shown in Fig. 3 including the power source and the acceleration module.

Four thermistors were applied to the blades on the roller body with a thermally conductive epoxy adhesive (Keratherm ${ }^{\circ}$ Bond $100 \mathrm{RT}$ ). The sensors were always glued in pairs at a distance of $9 \mathrm{~mm}$ and $25 \mathrm{~mm}$ from the blade edge. The sensors have been calibrated in a climatic chamber (POL-EKO-APARATURA type ST 1 COMF). A correction line is determined, which enables a linear correction for each sensor. The temperature range from $10{ }^{\circ} \mathrm{C}$ to $70{ }^{\circ} \mathrm{C}$ is calibrated in steps of $5 \mathrm{~K}$ for

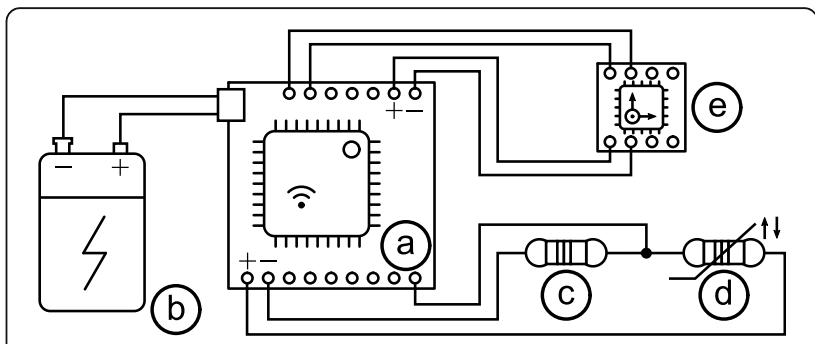

Fig. 3 Schematic of circuit with microcontroller (a), battery (b), reference resistor $(\mathbf{c})$, thermistor $(\mathbf{d})$ and acceleration module $(\mathbf{e})$

the sensors. The relative deviations are limited to $\pm 1 \mathrm{~K}$ after calibration.

\subsection{Measurement of the roller turning speed}

The turning speed of the blade roller is lower during the shaving process than in the load-free state. This behavior results from the drive with asynchronous motors, which are subject to slip under load. The acceleration module of type H3LIS331DL (SparkFun Electronics) is suitable for measuring accelerations up to $\pm 400 \cdot 9.81 \mathrm{~m} \cdot \mathrm{s}^{-2}$ with $1 \mathrm{kHz}$ data rate. The sensor allows the measurement of the centripetal acceleration $a_{\mathrm{cp}}$ since it is mounted as well on the turning roller with radial distance $r_{\text {Sensor }}$ to the axis of rotation. The acceleration can be $n_{\text {Motor }}$ with formula (3)

$$
n_{\text {Motor }}=\frac{\sqrt{a_{\mathrm{cp}} \cdot r_{\text {Sensor }}}}{2 \cdot \pi \cdot r_{\text {Sensor }}} \cdot 60 \frac{\mathrm{s}}{\mathrm{min}}
$$

The radial distance $r_{\text {Sensor }}$ is determined to be 111.55 $\mathrm{mm}$ by measuring the acceleration $a_{\mathrm{cp}}$ during idle speed $n_{\text {cylinder }}$ at $1000 \mathrm{~min}^{-1}$.

\subsection{Thermal modelling with finite element method}

The calculation of temperatures at positions inaccessible to sensors is possible with the help of modeling. The aim of the simulation is an estimation of the maximum temperatures at the cutting surface in contact with the product. The necessary geometrical data are available for the construction of the model, from which a volume model can be derived. The modelling is carried out with the program FreeCAD v0.18.4 and the integrated simulation with CalculiX [17]. The CAD model with the simulation setup is documented in the supplement as Additional file 1 . The heat generated by friction between the hide and the frontal surface of the knives is modeled as heat flow in the simulation. The quantification of the heat flow into the cutting tool is the fitting parameter and will be matched with the experimentally determined temperatures. The thermal influx $\dot{Q}_{\text {In }}$ is assumed to be uniform over the cut surface of the blade. For the simulation, the heat transfer from the metallic surfaces to the 
surrounding air has to be specified. The properties of the material steel listed in Table 2 are taken into account.

The operation of the shaving machine in steps with load and idle phases requires a transient simulation. Due to the high computational intensity of transient simulations, a simplification of the model was made to reduce the amount of volume to be calculated. Thereby, mainly symmetrical conditions have been used. Figure 4 shows the changes to the model step by step.

The roll body of the kniferoller (a) is centersymmetrical if the shaft journals are neglected. A model of the symmetric half cut (b) does not represent a loss of information, because the same behaviour can be expected on the second half. The 20 helical blades with equidistant spacing on the cylinder circumference give a further symmetry. The screw-like reduction is shown in (c). The original shape (b) can be reproduced rotationally symmetrically from 20 individual elements of (c). Finally, the symmetric helical shape (c) can be reduced in the pitch extrusion length to $1 \%$ of one revolution (d). The volume reduction saves computing time, which is used for increased mesh accuracy and smaller time steps. Due to the simplification of the model no conclusions can be drawn regarding mechanical stresses.

\subsection{Calculating the heat transfer coefficient}

The calculation of the value for the heat transfer coefficient $\alpha_{\text {roller-air }}$ is necessary for modelling the temperature of the blade. The knife roller is constantly surrounded by ambient air. As soon as there is a difference in temperature between the roller and the surrounding medium, heat transfer occurs. The heat transfer is calculated according to the investigations of Gnielinski [18]. The heat transfer coefficient $\alpha_{\text {roller-air }}$ is determined according to formula (4).

$$
\alpha_{\text {roller-air }}=\frac{\lambda_{\text {air }}}{l_{\text {characteristic }}} \cdot N u
$$

For the thermal conductivity coefficient $\lambda_{\text {air }}$ is given at the ambient temperature of $293 \mathrm{~K}$ with a value of 25.87 $\mathrm{mW} \cdot \mathrm{m}^{-1} \cdot \mathrm{K}^{-1}$. To determine the characteristic length

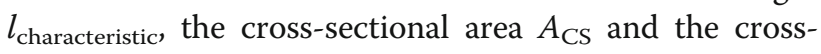

Table 2 Relevant material properties of steel

\begin{tabular}{lll}
\hline Variable & Value & Description \\
\hline$\rho_{\text {steel }}$ & $7900 \mathrm{~kg} \cdot \mathrm{m}^{-3}$ & Density \\
$v_{\text {steel }}$ & 0.3 & Poisson Ratio \\
$E_{\text {steel }}$ & $210 \mathrm{GPa}$ & YOUNGS Modulus \\
$c_{\text {steel }}$ & $590 \mathrm{~J} \cdot \mathrm{kg}^{-1} \cdot \mathrm{K}^{-1}$ & Specific Heat \\
$\lambda_{\text {steel }}$ & $43 \mathrm{~W} \cdot \mathrm{m}^{-1} \cdot \mathrm{K}^{-1}$ & Thermal Conductivity \\
$a_{\text {steel }}$ & $12 \cdot 10^{-6} \mathrm{~K}^{-1}$ & Thermal Expansion Coefficient \\
\hline
\end{tabular}

sectional perimeter $U_{\mathrm{CS}}$ are related to the U-shaped profile between the blades in formula (6). The blades behave similar to fins on a heat exchanger. The distance between two blades $s_{\text {ortho }}$ is determined according to formula (5).

$$
s_{\text {ortho }}=\frac{\pi \cdot d_{\text {cylinder }}}{n_{\text {blade }}} \cdot \sin \left(\arctan \left(\frac{p_{\text {blade }}}{\pi \cdot d_{\text {cylinder }}}\right)\right)
$$

The distance between two blades is used to determine

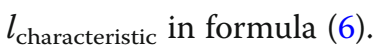

$$
l_{\text {characteristic }}=\frac{4 \cdot A_{\mathrm{CS}}}{U_{\mathrm{CS}}}=\frac{4 \cdot s_{\text {ortho }} \cdot h_{\text {blade }}}{s_{\text {ortho }}+2 \cdot h_{\text {blade }}}
$$

The remaining NUSSELT number $\mathrm{Nu}$ must be calculated to solve formula (4). Different calculation rules are used depending on the flow behavior. In this case, the calculation for the turbulent flow case is used [7], because the spiral always cuts and swirls the air again and the REYNOLDS number is correspondingly high.

$$
N u=\frac{\left(0.037 \cdot \operatorname{Re}^{-0.2}\right) \cdot \operatorname{Re} \cdot \operatorname{Pr}}{1+12.7 \cdot \sqrt{0.037 \cdot \operatorname{Re}^{-0.2}} \cdot\left(\operatorname{Pr}^{\frac{2}{3}}-1\right)}
$$

The calculation rule of $\mathrm{Nu}$ [7] depends on the REYNOLDS number $R e$ and the PRANDTL number Pr. The REYNOLDS number $R e$ is determined by formula (8) with the kinematic viscosity $v_{\text {air }}$ from Table 3 .

$$
R e=\frac{w_{\text {air }} \cdot l_{\text {characteristic }}}{v_{\text {air }}}
$$

The velocity of the overflowing medium air $w_{\text {air }}$ is determined from the perimeter of the mean height of the U-shaped profile and the rotational speed in formula (9).

$$
w_{\text {air }}=\pi \cdot\left(d_{\text {cylinder }}+h_{\text {blade }}\right) \cdot n_{\text {cylinder }}
$$

The PRANDTL number $\mathrm{Pr}$ is calculated according to formula (10).

$$
\operatorname{Pr}=\frac{\nu_{\text {air }} \cdot \rho_{\text {air }} \cdot c_{\text {pair }}}{\lambda_{\text {air }}}
$$

The remaining unknown variables are taken from tables on substance characteristics [19] and are listed in Table 3 for an ambient temperature of $20^{\circ} \mathrm{C}$ and an ambient pressure of $0.1 \mathrm{MPa}$.

The heat transfer coefficient $\alpha_{\text {roller-air }}$ of $116 \mathrm{~W} \cdot \mathrm{m}^{-2} \cdot \mathrm{K}^{-1}$ is calculated by inserting the variables in the equations. This value is within the typical values [20] for forced convection with gases from 20 to $300 \mathrm{~W} \cdot \mathrm{m}^{-2} \cdot \mathrm{K}^{-1}$ and applied in the simulation. A study on heat transfer on rotating cylinders [21] concludes that the heat transfer coefficient is reduced due to local circulation of air around rapidly moving cylinders. In a further investigation on heat 

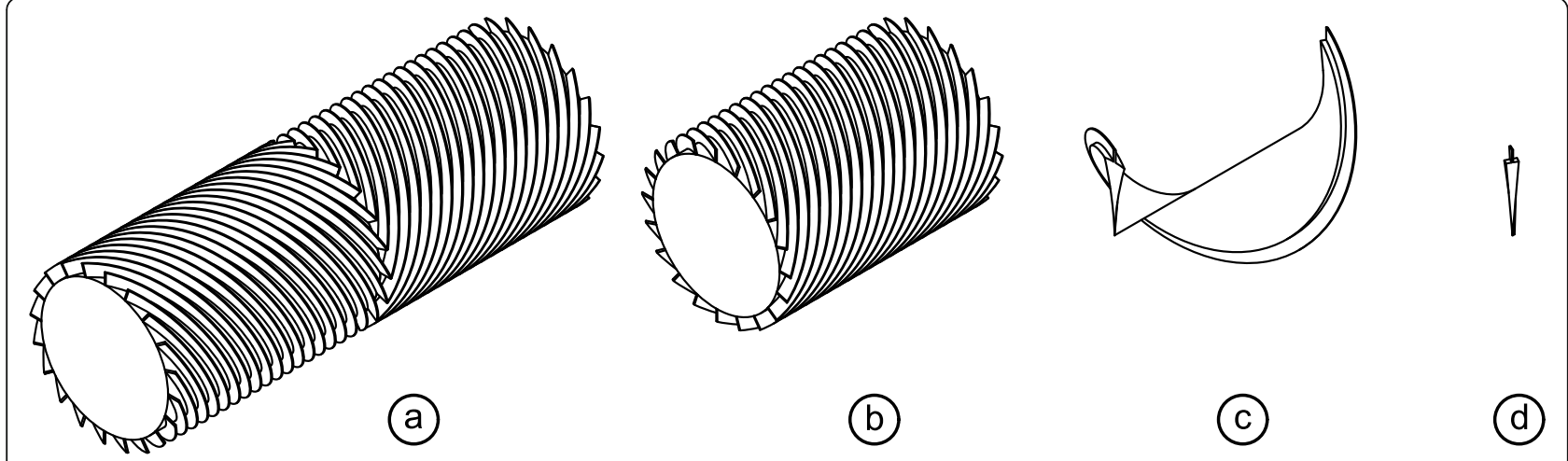

Fig. 4 Model reduction. a Basic Model of the Kniferoller. b Symmetric half cut. c Symmetric helical shape. d Small piece of the helical shape

transfer on pipes with fins it could be shown that even with a forced jet a change of the NUSSELT number between a cylinder with fins and a cylinder without fins is significant [22]. The consideration of the increased surface area is therefore also retained in this calculation.

\section{Results}

\subsection{Thermography}

The thermographic measurement allowed to monitor the temperature development of the whole rollerblade and the processed leather simultaneously. The measurements with the thermocouple during machine standstill resulted in a temperature of $24{ }^{\circ} \mathrm{C}$ before the tests and a temperature of $27^{\circ} \mathrm{C}$ after the tests. Measurements are taken in the middle of the blade roll. With the aid of these two measuring points, an emissivity $\varepsilon$ of 0.97 is determined. This emissivity is higher than the values found in the literature. The blades have an unspecified but very dark layer due to a passivated anti-corrosion treatment. The thickness of such oxidation layers has a strong influence on the emissivity [23]. Figure 5 shows a pictogram of the thermographically examined area (c) with an image before (b) and after shaving (c) from the same video sequence.

The pictures show a section of the central area of the roller body (Fig. 5). The comparison of the images clearly shows a heating caused by the process. Before the shaving process, the base body is warmer than the blades indicated by a lighter blue of the roller base compared to the blades (Fig. $5 \mathrm{~b}$ ). After the shaving process, the image

Table 3 Selected material values for the surrounding fluid

\begin{tabular}{lll}
\hline Variable & Value & Description \\
\hline$\rho_{\text {air }}$ & $1.189 \mathrm{~kg} \cdot \mathrm{m}^{-3}$ & Density \\
$c_{\mathrm{p} \text { air }}$ & $1.006 \mathrm{JJ} \cdot \mathrm{kg}^{-1} \cdot \mathrm{K}^{-1}$ & Specific thermal capacity \\
$\lambda_{\text {air }}$ & $25.87 \mathrm{~mW} \cdot \mathrm{m}^{-1} \cdot \mathrm{K}^{-1}$ & Thermal conductivity \\
$V_{\text {air }}$ & $153.2 \cdot 10^{-7} \mathrm{~m}^{2} \cdot \mathrm{s}^{-1}$ & Kinematic viscosity \\
\hline
\end{tabular}

shows a remarkably higher temperature for the blades exceeding $40^{\circ} \mathrm{C}$ after shaving one hide (Fig. 5c). The images are taken from an infrared video which is part of the supplementary material as Additional file 2. In the video it can be seen, that the chips shaved from the leather show hardly any increase in temperature. From a series of 25 videos, an average temperature of $29^{\circ} \mathrm{C}$ had been measured before the shaving process and $42{ }^{\circ} \mathrm{C}$ at the end of the process for the blades. These temperatures are approximate values since the temperature determination by thermography is influenced by the constant movement of the blades and the resulting angular deviations, altering reflections and the use of a mirror for image capture, which results in a reduction of the emission. Furthermore, only a single skin could be shaved when the videos were recorded, as the shaves flinging out of the machine quickly cover the mirror and thus prevent the acquisition of thermographic data. A continuous measurement of the temperature is thus not possible. The resulting temporal intervals between the consecutively taken thermographic measurements allow the roller and the blades to cool down. This experimental set up does not represent the conditions in an industrial shaving process with continuous machine operation. The results of the thermography should be cross-checked, because of the error-prone calibration. For a more precise determination of the temperature, thermistor measurements were used. Thermographic data show however, that leather and shavings are heated much less compared to the knife during shaving of one single hide. Similar heating of the blades in the entire area of contact of blades and hide was confirmed by video recordings of the entire roller.

\subsection{Thermistor measurements}

Temperature measurements by thermistors do not rely on thermal radiation and have the advantage over thermography of a precise precalibration of the thermal semiconductors used. They allows a continuous 


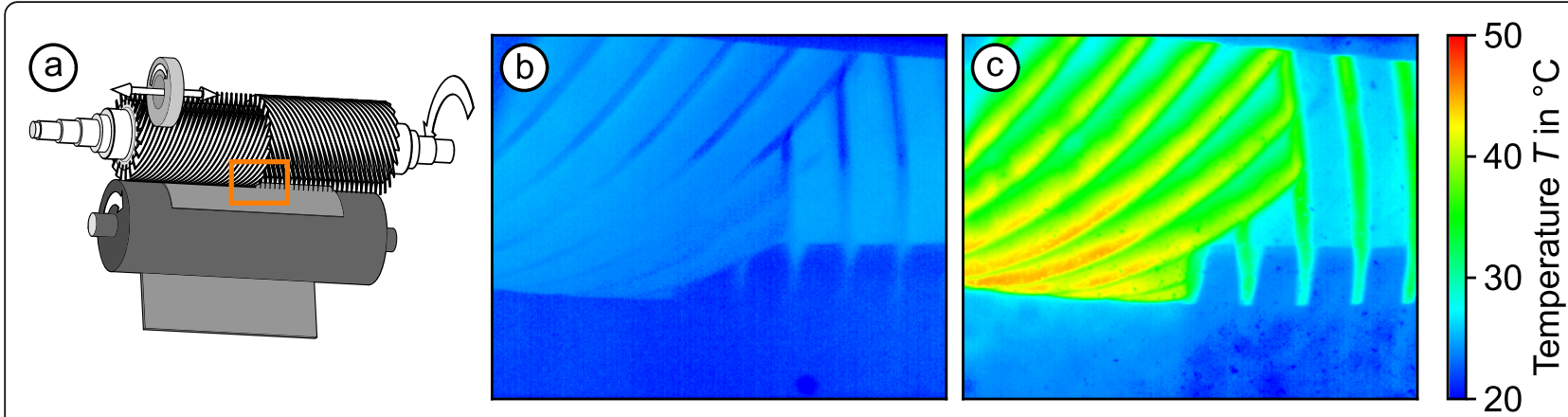

Fig. 5 Infrared imaging of the roller blade before (b) and after (c) shaving. The marked area in the pictogram (a) indicates the section shown in the thermographic images

temperature measurement throughout the whole process on an industrial scale at selected points of the roller and blade. Because of the precise and continuous data acquisition, thermistor measurements are a sensible and reliable basis for process simulation.

The temperature measurements during operation are carried out for the materials Wet Blue and Wet White. Eleven hides per type of pre-tanning were processed. Temperature curves and engine speed are shown in Figs. 6 and 7. The numerical data of the figures can be found in Supplementary files 3 for Wet Blue and 4 for Wet White.

If the speed drops below $997 \mathrm{~min}^{-1}$, the machine runs under load due to leather shaving. The different steps during shaving a whole hide, which are described in Chapter 1.2, can be clearly distinguished in the temperature curves. The first temperature rise under load represents step I (shaving $2 / 3$ of the hide from tail). During step II (removing the hide from the machine and turning it) no shaving takes place and no load is detected. The roller moves without contact to any material and cool down to a certain extent. The temperature drops until the hide is shaved from the neck in step III. The machine is again under load and temperatures rise both at the base and the edge position of the thermistors is detectable. Step IV (the hide is removed from the machine and stacked next to the machine) shows again a drop in temperature since no shaving is performed. Due to the prolonged time with no shaving in step IV in comparison to step II, cooling is more pronounced at the end of the cycle of shaving one hide. Shaving the next hide, all steps are run through again. The cylinder temperature $T_{\text {Base }}$ fluctuates with $\pm 1.5 \mathrm{~K}$ around an average temperature of $47^{\circ} \mathrm{C}$. The measured temperature near the blade edge $T_{\text {Edge }}$ shows maximum temperatures $T_{\text {EdgeMax }}$ of $67^{\circ} \mathrm{C}$ during operation. The largest temperature difference occurs when changing the hide. The temperature at the blade edge rises and falls more sharply than the temperature at the base. If no shaving is performed for $30 \mathrm{~s}$, the temperature at the blade edge drops below the temperature at the base as indicated after shaving of 11 hides in Fig. 6. The temperature curve measured when shaving Wet White behave similarly (Fig. 7).

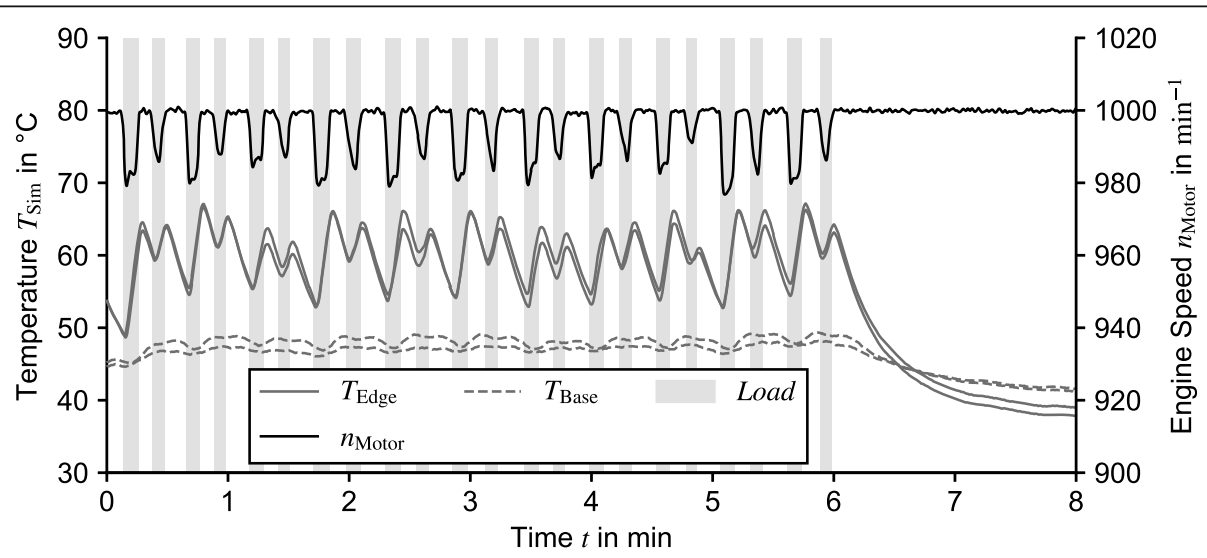

Fig. 6 Temperature and motor speed measurement for Wet Blue during shaving. Grey lines represent temperatures $T_{\text {Edge }}$ Close to the edge of

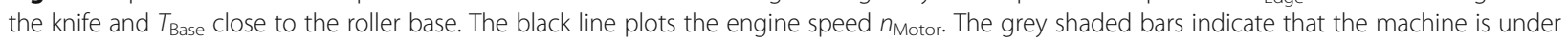
load due to loss in engine speed 


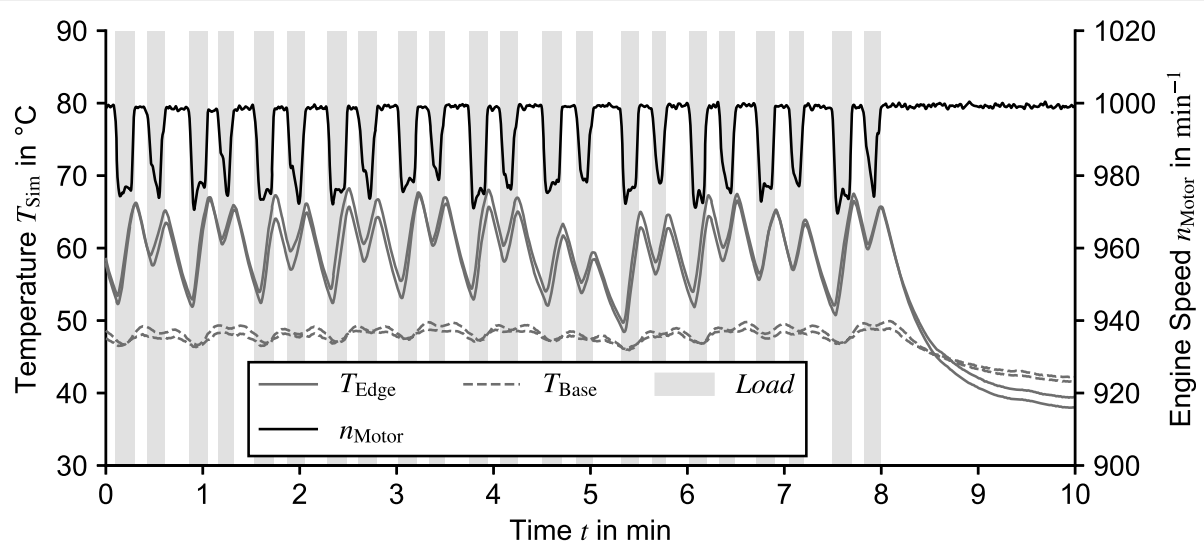

Fig. 7 Temperature and motor speed measurement for Wet White during shaving. Grey lines represent temperatures $T_{\text {Edge }}$ Close to the edge of the knife and $T_{\text {Base }}$ close to the cylindrical roller surface. The black line plots the engine speed $n_{\text {Motor. }}$ The grey shaded bars indicate that the machine is under load due to loss in engine speed

Compared to wet blue, the cycle time per skin for shaving Wet White is higher due to the lower feed rate of the wet white skins. The largest temperature difference occurs again when changing the hide. The temperature near the blade edge $T_{\text {Edge }}$ has a slightly higher maximum of $68^{\circ} \mathrm{C}$ during operation compared to the results for Wet Blue. The cylinder temperature $T_{\text {Base }}$ fluctuates with $\pm 1.5 \mathrm{~K}$ around a temperature of $47^{\circ} \mathrm{C}$ for Wet White.

\subsection{Transient finite element simulation}

The simulation uses the calculated heat transfer coefficient $\alpha_{\text {roller-air }}$ of $116 \mathrm{~W} \cdot \mathrm{m}^{-2} \cdot \mathrm{K}^{-1}$ for the transition from the metallic surfaces to the surrounding air. The ambient air outside the machine has a temperature of $23.5 \pm$ $0.5^{\circ} \mathrm{C}$. However, during shaving the temperature inside the machine casing rises. Therefore, the simulated ambient temperature was set to $30^{\circ} \mathrm{C}$. The initial temperature of the kniferoller is set to $47^{\circ} \mathrm{C}$ according to the average temperature of $T_{\text {Base }}$. The load conditions from the measurements in chapter 3.2 are used as input data for the simulation. The energetic input $Q_{\text {In }}$ at the surface of the knife in contact with the leather was iteratively adjusted with steps of $25 \mathrm{~W}$ in the simulation. The criterion of the adjustment is a most similar reproduction of the measured temperatures $T_{\text {Edge }}$ and $T_{\text {Base }}$. For the adjustment between the measured values and the simulation, the temperatures are evaluated at the positions of the sensors of the real test in the simulation model. Simulated temperatures are denoted as $T_{\text {SimEdge }}$ and $T_{\text {SimBase }}$ and are set at a distance of 9 and $25 \mathrm{~mm}$ from the blade edge. An additional evaluation plane is set at a distance of $2 \mathrm{~mm}$ from the blade edge to estimate temperatures near to the contact zone between the blade edge and hide where fibres are cut during shaving and friction occurs. The simulated temperature nearest to the contact zone between blade and leather is denoted as $T_{\text {SimZone }}$. Figure 8 illustrates the result for one time step of the simulation using the model reduction illustrated in Fig. 4.

The energy input $Q$ In by friction takes place at the contact surface of the cutting tool and is shown symbolically. The blade is cooled by forced convection due to the rotational movement of the roller. The cylinder surface also emits energy by convection. Arrows show the energy input and loss. The small piece of a helical shape from Fig. 4 is divided into a mesh of tetrahedron shaped

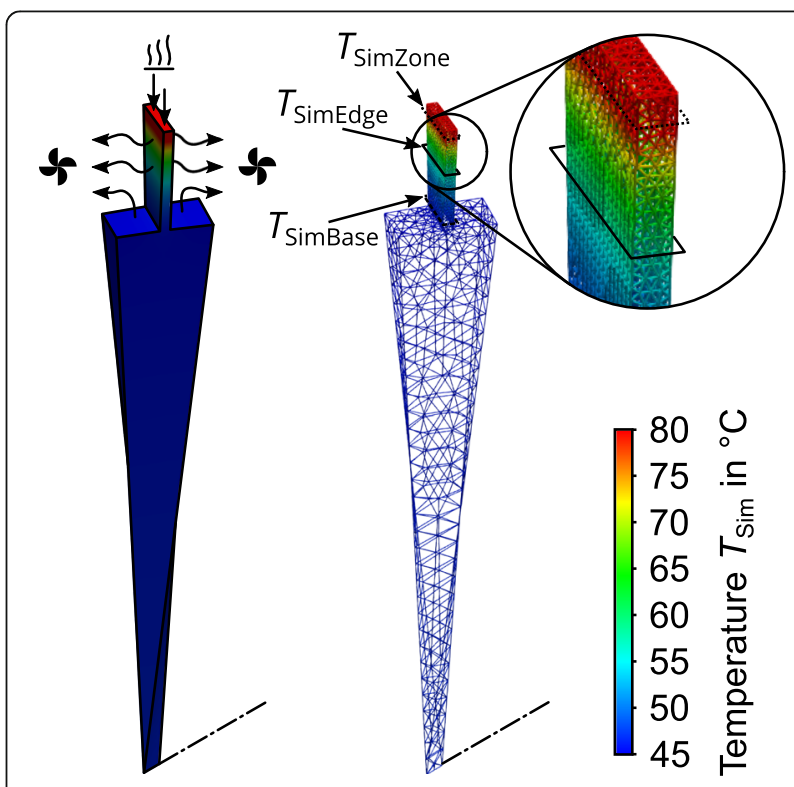

Fig. 8 Surface plot of a simulation step for the reduced model of the kniferoller with symbols for heat input and convection (left). The temperatures are evaluated on three levels in the wireframe model of the mesh resolution (right) 
elements with an intermediate support point along each axis. These elements contain three corner nodes and a total of 10 nodes. The maximum edge length is globally limited to $5 \mathrm{~mm}$ and in the area of the knife to $1 \mathrm{~mm}$. The detailed view of the surface plot in Fig. 8 shows the load state during heating. The temperature difference within an element is less than $2 \mathrm{~K}$ in a time step size of $0.2 \mathrm{~s}$, which is considered to be a sufficient temperature steadiness. The simulation shows three distinguishable areas in the temperature profile shown in the wireframe model (Fig. 8, right). The indicated lines correspond to the position of the thermistors and the simulated temperature close to the cutting zone of the blade. Figures 9 and 10 show the results of the simulated temperatures over time for Wet Blue and Wet White. Measured temperatures are shown in light grey lines for comparison.

The heat influx $Q$ In at the contact surface of the blade with the hide is fitted to be $600 \mathrm{~W}$ per $528 \mathrm{~mm}$ cylinder height and per blade to match the recorded curves for Wet Blue. During the first minute, the measured values exceed the simulated values significantly. The simulated temperature of the blade edge $T_{\text {SimEdge }}$ is in the range of $56^{\circ} \mathrm{C}$ to $66^{\circ} \mathrm{C}$ which is only slightly different from the measured temperature $T_{\text {Edge. }}$ The simulated temperature close to the cutting zone $T_{\text {Simzone predicts temperatures up to }}$ $85.0^{\circ} \mathrm{C}$. The results of the transient simulation for Wet Blue are attached in the supplement video (Additional file 5).

The simulation is also performed with the cycle times for Wet White. The heat influx $\dot{Q}_{\text {In }}$ had to be reduced to $525 \mathrm{~W}$ per $528 \mathrm{~mm}$ cylinder height and per blade due to the different feed rate. Figure 10 shows the simulation results for Wet White with corresponding time steps.

The heat influx $\dot{Q}_{\text {In }}$ at the contact surface of the blade with the hide is fitted to be $525 \mathrm{~W}$ per $528 \mathrm{~mm}$ cylinder height and per blade to match the recorded curves for Wet White samples and is therefore significantly lower compared to the $600 \mathrm{~W}$ per $528 \mathrm{~mm}$ of Wet Blue samples. As for Wet Blue, larger deviations are found in the first minute. The temperatures $T_{\text {SimEdge }}$ are calculated in a range from $53^{\circ} \mathrm{C}$ to $67^{\circ} \mathrm{C}$, which is in good correlation with the measured temperatures $T_{\text {Edge }}$. The maximum temperatures of $88.5^{\circ} \mathrm{C}$ in the prediction of the simulation at the machining zone $T_{\text {Simzone }}$ are remarkably similar to the simulation results of Wet Blue. The results of the transient simulation for Wet White are likewise included in the supplement video (Additional file 6).

\subsection{Analysis of shaved hides}

Wet Blues had an initial thickness of $2.4 \mathrm{~mm}$ to $2.5 \mathrm{~mm}$. After the process, a thickness of $1.9 \mathrm{~mm}$ was achieved. The Wet White hides had an initial thickness of $1.8 \mathrm{~mm}$ to $1.9 \mathrm{~mm}$ and a target thickness of $1.0 \mathrm{~mm}$. The different target thickness of wet White and Wet Blue hides is due to the different requirements of the final products made from these skins.

The temperature of denaturation was measured by differential scanning calorimetry (DSC). For Wet Whites, onset temperature $T_{\mathrm{D}}{ }^{\text {onset }}$ of denaturation was $81.0 \pm$ $0.9^{\circ} \mathrm{C}$, maximum temperature $T_{\mathrm{D}}{ }^{\max }$ was $85.0 \pm 0.6^{\circ} \mathrm{C}$. The onset temperature for Wet Blues was $103.2 \pm 1.4{ }^{\circ} \mathrm{C}$ and maximum temperature was determined to be $107.7 \pm 1.4^{\circ} \mathrm{C}$. No signs of denaturation where observed on all hides such as partly gelation of shavings.

When comparing the dry matter content of a hide before and after shaving no overall loss of water was observed. A significant difference in moisture loss

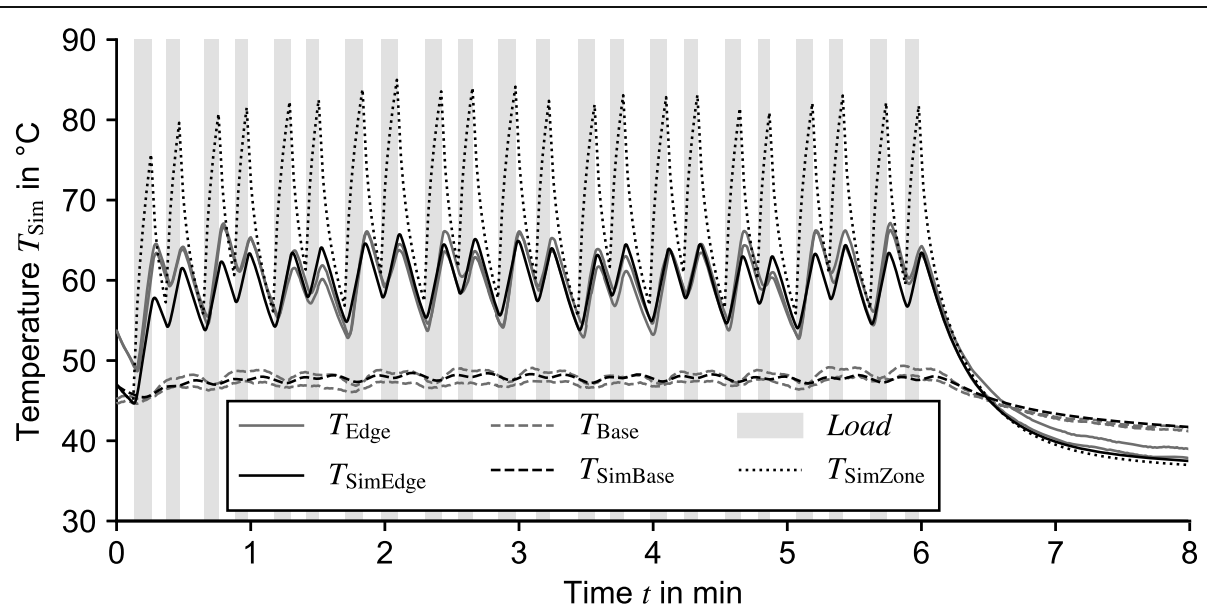

Fig. 9 Temperature simulation for Wet Blue during shaving. The black curve represents the simulated temperature $T_{\text {simEdge }}$ and corresponds to the grey curve of the measured temperature $T_{\text {Edge. }}$. The black dashed curve represents the simulated temperature $T_{\text {simBase }}$ near the roller base and corresponds to the grey dashed curve of $T_{\text {Base. }}$. The dotted black curve displays the simulated temperature in the contact zone $T_{\text {simzone. }}$ The grey shaded vertical bars indicate when the machine is under load 


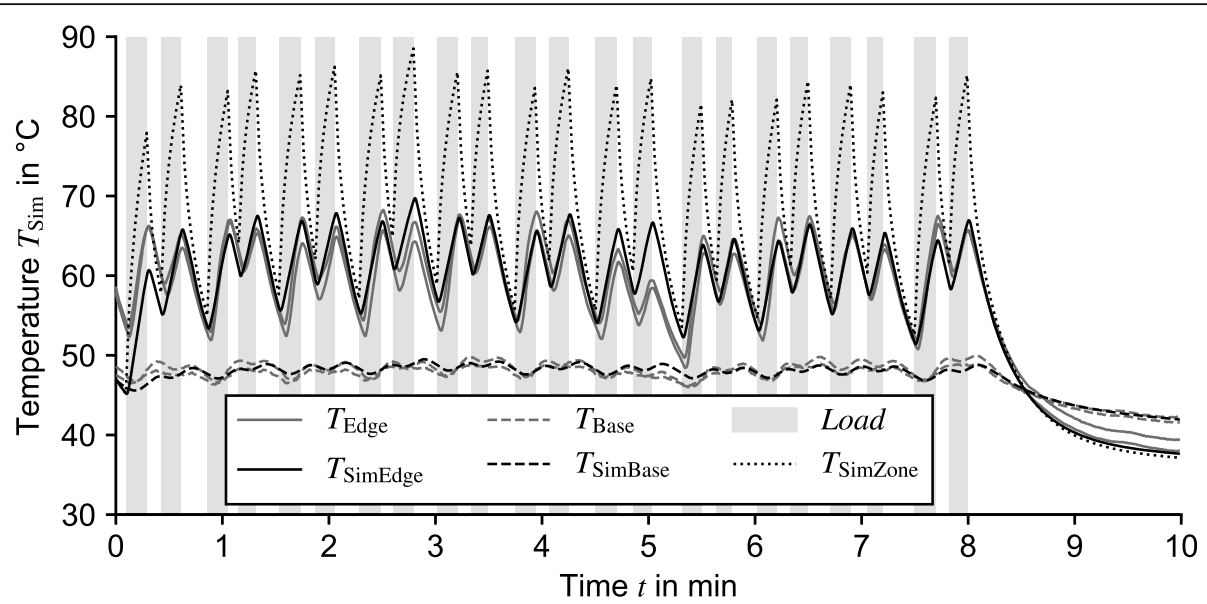

Fig. 10 Temperature simulation for Wet White during shaving. The black curve represents the simulated temperature $T_{\text {simEdge }}$ and corresponds to the grey curve of the measured temperature $T_{\text {Edge. }}$. The black dashed curve represents the simulated temperature $T_{\text {simBase }}$ near the roller base and corresponds to the grey dashed curve of $T_{\text {Base. }}$. The dotted black curve displays the simulated temperature in the contact zone $T_{\text {Simzone. }}$ The grey shaded vertical bars indicate when the machine is under load

between Wet Blue and Wet White hides could not be determined.

\section{Conclusion}

Thermography and measurements with thermistors show both an increase in the temperature of the knife roller during the shaving process, which is thus verified. The measuring methods are not intended for a direct comparison. Thermography shows an overall image, but cannot be used for temperature measurement in consecutively shaved hides in an industrial processing frequency. In contrast, the thermistors measure the blade temperature continuously at specific points but do not show the temperature distribution along the roll. Both measuring methods show an increase in temperature and thus verify the influx of heat. The results of the process simulation and the obtained simulated temperature curves are remarkably similar to the measured temperature curves. Shaving a wet blue hide of $2000 \mathrm{~mm}$ width with 20 knives on the knife roller generates about $45 \mathrm{~kW}$ of heat according to the simulation. This corresponds to more than $50 \%$ of the nominal motor power output of the main drive. Shaving the Wet Blue samples generated $14 \%$ more heat at the knife roller than shaving the same amount Wet White samples. The relatively small difference can be attributed to the different feed rates, initial thicknesses, target thicknesses and ablation heights. An exact allocation requires further investigations.

The simulated maximum temperatures of $88.5^{\circ} \mathrm{C}$ at the blades contact zone exceed the temperature of denaturation $T_{\mathrm{D}}{ }^{\max }$ of $85.0^{\circ} \mathrm{C}$ for Wet Whites. Since no signs of denaturation where observed, the simulated temperatures at the cutting edge may not result in denaturation due to the short contact time of the leather and cooling by evaporation. The thesis is supported by the thermographic data which hardly show a temperature increase of the shavings whereas the temperature of the blades rises significantly (see video (Additional file 1) in the supplement). Damage of Wet Blues due to blade temperature will not occur because of the markedly higher temperature of denaturation. These experiments and the simulation impressively confirm, that untanned hides with a $T_{\mathrm{D}}^{\max }$ of $60^{\circ} \mathrm{C}$ have to be pretanned to survive the shaving process on machines.

Further experiments with different processing speeds and different material thicknesses should be carried out to extend the validity of the model. Calculations on machines will have to be carried out with the recorded and simulated values concerning expansions and thermally induced stresses. Measures to reduce the friction between blade and leather should be investigated to reduce the load on the machine for higher energy efficiency.

\section{Supplementary Information}

The online version contains supplementary material available at https://doi. org/10.1186/s42825-021-00057-0.

\section{Additional file 1. \\ Additional file 2. \\ Additional file 3. \\ Additional file 4. \\ Additional file 5. \\ Additional file 6.}

Acknowledgements

We thank HEUSCH GmbH \& Co. KG (Aachen, Germany) for their participation in the project and SÜDLEDER GmbH (Rehau, Germany) for their support in experiments. 


\section{Authors' contributions}

TW recorded, analyzed and interpreted the thermal measurement data. TW carried out the calculation and finite element analysis and was a major contributor in writing the text. AM performed all tests regarding the leather properties and was writing the corresponding text passages. JPM and MM formulated the conclusion and interpretation. All authors read and approved the final manuscript

\section{Funding}

This work is funded by the German Federal Ministry for Economic Affairs and Energy within the Central Innovation Program for small and medium-sized enterprises.

\section{Availability of data and materials}

All data generated or analyzed during this study are included in this published article and its supplementary information files.

\section{Declaration}

\section{Competing interests}

The authors declare that they have no competing interests.

\section{Author details}

${ }^{1}$ Chair of Processing Machines and Processing Technology, Technische Universität Dresden, 01062 Dresden, Germany. ${ }^{2}$ Forschungsinstitut für Leder und Kunststoffbahnen (FlLK) gGmbH, MeißnerRing 1-5, 09599 Freiberg, Germany.

\section{Received: 7 August 2020 Accepted: 21 March 2021}

Published online: 15 July 2021

\section{References}

1. Broughton WE, Brophy JJ. Technical Problems of the Tanning Industry. J Am Inst Electric Engineers. 1922:646-9.

2. Reich G. From collagen to leather - the theoretical background. Ludwigshafen: BASF Servicecenter; 2007.

3. Bonfig KW. Temperatursensoren Renningen-Malmsheim: expert verlag; 1995. https://doi.org/10.1002/cite.330680725.

4. Muraka PD, Barrow G, Hinduja S. Influence of the process variables on the temperature distribution in orthogonal machining using the finite element method. Int J Mech Sci. 1979;21(8):445-56. https://doi.org/10.1016/0020-74 03(79)90007-9.

5. Grzesik W, Bartoszuk M, Nieslony P. Finite element modelling of temperature distribution in the cutting zone in turning processes with differently coated tools. J Mater Process Technol. 2005;164-165:1204-11. https://doi.org/10.1016/j.jmatprotec.2005.02.136.

6. Stephenson DA, Jen TC, Lavine AS. Cutting tool temperatures in contour turning: transient analysis and experimental verification. Journal of Manufacturing Science and Engineering. 1997;119(4A):494-501. https://doi. org/10.1115/1.2831179.

7. Heidmann E. Fundamentals of Leather Manufacture; pp.111: Roether. Darmstadt: Roether; 1993.

8. Schröpfer M, Meyer M. DSC investigation of bovine hide collagen at varying degrees of crosslinking and humidities. Int J Biol Macromol. 2017;103:120-8. https://doi.org/10.1016/j.jjbiomac.2017.04.124.

9. Covington AD, Lampard GS, Hancock RA, loannidis IA. Studies on the origin of hydrothermal stability: a new theory of tanning. J Am Leather Chem Assoc. 1998:93(4):107-20.

10. Landmann W. The Machines in the Tannery. Dewsbury: World Trades Publishing; 2003.

11. Thomsen EG, MacDonald AG, Kobayashi S. Flank friction studies with carbide tools reveal sublayer plastic flow. J Eng Ind. 1962;84(1):53-62. https://doi.org/10.1115/1.3667438.

12. Witt $T$, Klüver $E$, Nikowski $A$, Meyer M. Leather shaving - a new approach for understanding the shaving process - 242. XXXV IULTCS Congress Dresden 2019. Dresden; 2019.

13. Schuster N, Valentin GK. Infrarotthermographie. Berlin: Wiley-VCH; 2004.

14. Soerensen D, Clausen S, Mercer JB, Pedersen LJ. Determining the emissivity of pig skin for accurate infrared thermography. Comput Electron Agric. 2014;109:52-8. https://doi.org/10.1016/j.compag.2014.09.003.
15. Peeters J, Ribbens B, Dirckx J, Steenackers G. Determining directional emissivity: Numerical estimation and experimental validation by using infrared thermography. Infrared Phys Technol. 2016;77:344-50. https://doi. org/10.1016/j.infrared.2016.06.016.

16. Steinhart J, Hart S. Calibration curves for thermistors. Deep-Sea Res Oceanogr Abstr. 1968;15(4):497-503. https://doi.org/10.1016/0011-7471 (68) $90057-0$.

17. Dhondt G. The finite element method for three-dimensional thermomechanical applications. Chichester: John Wiley \& Sons Ltd; 2004.

18. Gnielinski V, Gnielinski V. Berechnung mittlerer Wärme-und Stoffübergangskoeffizienten an laminar und turbulent überströmten Einzelkörpern mit Hilfe einer einheitlichen Gleichung. Forschung Ingenieurwesen A. 1975:41(5):145-53. https://doi.org/10.1007/BF02560793.

19. Verein Deutscher Ingenieure. VDI heat atlas. 2nd ed. Berlin: Springer; 2010

20. Jiji LM. Heat convection. 2nd ed. Berlin: Springer; 2009. https://doi.org/10.1 007/978-3-642-02971-4.

21. Chiou CC, Lee SL. Forced convection on a rotating cylinder with an incident air jet. Int J Heat Mass Transf. 1993;36(15):3841-50. https://doi.org/10.1016/ 0017-9310(93)90064-D.

22. Gori F, De Nigris F, Pippione E, Scavarda G. Cooling of a Finned Cylinder by a Jet Flow of Air. Process Industries. ASME 2002 International Mechanical Engineering Congress and Exposition. 2002; p. 117-22. https://doi.org/1 0.1115/IMECE2002-39596

23. luchi T, Furukawa T, Wada S. Emissivity modeling of metals during the growth of oxide film and comparison of the model with experimental results. Appl Opt. 2003:2317-26. https://doi.org/10.1364/AO.42.002317.

\section{Publisher's Note}

Springer Nature remains neutral with regard to jurisdictional claims in published maps and institutional affiliations.

\section{Submit your manuscript to a SpringerOpen ${ }^{\circ}$ journal and benefit from:}

- Convenient online submission

- Rigorous peer review

- Open access: articles freely available online

High visibility within the field

- Retaining the copyright to your article

Submit your next manuscript at $\boldsymbol{\nabla}$ springeropen.com 